\title{
Effect of Excisional Goniotomy with the Kahook Dual Blade (KDB) on Surgically Induced Astigmatism
}

This article was published in the following Dove Press journal:

Clinical Ophthalmology

\author{
Matthew Hirabayashi $\mathbb{D}^{1,2}$ \\ Gurpal Virdi' \\ Joshua King $\mathbb{D}^{\prime}$ \\ Dayeong Lee' \\ Van Nguyen (iD ${ }^{1,2}$ \\ Jella $A n\left(D^{1,2}\right.$
}

'School of Medicine, University of Missouri, Columbia, MO, USA; ${ }^{2}$ Mason Eye Institute, Department of

Ophthalmology, University of Missouri, Columbia, MO, USA
Correspondence: Jella An

Mason Eye Institute, Department of Ophthalmology, University of Missouri,

3215 Wingate Court, Columbia, MO

6520I, USA

Tel + | 573-884-|3||

Fax + I 573-884-3330

Email anja@health.missouri.edu
Purpose: To determine the effect of Kahook Dual Blade goniotomy with phacoemulsification (Phaco-KDB) compared to phacoemulsification alone (Phaco) on surgically induced astigmatism (SIA).

Design: Prospective study.

Participants: Forty eyes of 28 patients treated with Phaco-KDB and 20 eyes of 13 patients treated with Phaco between 12/27/16 and 7/23/19 with a minimum 1 month follow-up were prospectively enrolled.

Methods: Corneal astigmatism was assessed pre- and post-operatively using the simulated $\mathrm{K}(\operatorname{simK})$ values from the Pentacam Holladay report.

Main Outcome Measures: SIA was compared between Phaco-KDB and Phaco groups using mean magnitude SIA, rate of $\geq 0.50$ D SIA, and SIA centroids.

Results: The difference in mean magnitude SIA was not statistically significant between Phaco-KDB and Phaco (mean $=0.28 \mathrm{D}$ and $0.25 \mathrm{D}$, respectively, $P=0.621$ ). The difference in the rate of $\geq 0.50$ D SIA was not statistically significant between Phaco-KDB and Phaco (11.6\% and $10.0 \%$, respectively, $P=1.00$ ). The SIA centroid for Phaco-KDB was $0.05 \mathrm{D} @$ $51^{\circ} \pm 0.40 \mathrm{D}$ and $0.07 \mathrm{D} @ 3^{\circ} \pm 0.32 \mathrm{D}$ for Phaco.

Conclusion: Neither the mean magnitude SIA nor the rate of astigmatic change $\geq 0.50$ D was significantly different between Phaco-KDB and Phaco groups. SIA centroids between groups showed comparable and negligible effect on corneal astigmatism. KDB combined with phacoemulsification may not significantly affect SIA compared to phacoemulsification alone based on postoperative topography and is likely an astigmatically neutral procedure.

Keywords: KDB, astigmatism, MIGS, surgically induced astigmatism

\section{Introduction}

With modern small incisions and the availability of astigmatism correcting techniques including limbal relaxing incisions, strategic wound placement, and toric IOLs, accurately predicting surgically induced astigmatism (SIA) is crucial for desired outcomes. ${ }^{1-3}$

Angle surgeries and Schlemm's canal micro-invasive glaucoma surgeries (MIGS) have grown in popularity due to their superior safety compared to conventional filtering surgery, and ability to be combined with cataract surgery with more predictable refractive outcomes. ${ }^{4-6}$ Kahook Dual Blade goniotomy (KDB, New World Medical, Rancho Cucamonga, CA) uses parallel blades to remove a nasal segment of trabecular meshwork (TM) enbloc. ${ }^{7}$ Like most MIGS, data on the SIA of KDB combined with phacoemulsification compared to phacoemulsification alone are lacking in the literature. ${ }^{8}$ 
Due to the anatomical relationship between the TM, peripheral iris, anterior chamber angle, and posterior cornea, patients who undergo sectoral excision of the TM may theoretically experience changes to any existing posterior corneal astigmatism. We have previously reported a case where a patient underwent Phaco-KDB in one eye and had differential refractive outcome due to changes in corneal astigmatism compared to his fellow eye where he had Phaco only. ${ }^{9}$ Others have reported neutral refractive outcome of $\mathrm{KDB}^{18}$ However, to our knowledge, no studies have evaluated the effect of KDB on surgically induced corneal astigmatism. We sought to determine if the SIA of PhacoKDB was different from that of Phaco alone, so surgeons can perform Phaco-KDB with confidence that their calculations are accurate without the need for special considerations.

\section{Methods}

After obtaining University of Missouri IRB approval $(\# 2,016,061)$ and informed consents, we enrolled all adult patients who had uncomplicated Phaco-KDB or Phaco alone in University of Missouri between 12/27/16 and 7/23/19 to complete repeat topography at a minimum of 1 month after surgery. Indications for Phaco-KDB included need for further reduction in IOP or medication burdens in patients with confirmed glaucoma with suspected TM dysfunction, including chronic angle-closure glaucoma with peripheral anterior synechiae. All patients had obtained visual acuity, manifest refraction, intraocular pressure, biometry and Pentacam (OCULUS Inc, Arlington, WA) topography as a part of routine preoperative workup. Those with insufficient quality imaging were excluded from the study. We also excluded patients who had any other procedures (eg, LRI, synechiolysis, endocyclophotocoagulation, use of sutures to wound) performed at the time of surgery. Some glaucoma patients received Phaco alone for various reasons including success with alternative therapy, bleeding predilection, insurance, patient preference or surgeon discretion. Data from a total of 42 eyes of 28 patients treated with Phaco$\mathrm{KDB}$ and 20 eyes of 13 patients who were treated with Phaco alone were analyzed. All astigmatism data including $\operatorname{simK} 1$, simK2, and axis obtained from the Holladay report and $1 \mathrm{~mm}$ and $8 \mathrm{~mm}$ concentric data from True Net Power were collected from preoperative and postoperative Pentacam results. Images of topography from the phenomenon we initially observed can be found in the case report referenced in the introduction. ${ }^{1}$

All Phaco incisions were temporal clear corneal, biplanar, and $2.4 \mathrm{~mm}$ in size. All KDB goniotomy was performed over 4 clock hours nasally by a single surgeon, followed by a standard phacoemulsification with a foldable intraocular lens insertion. At the end of the case, the majority of the viscoelastic was removed and $25 \%$ was left to prevent hyphema for all cases and care was taken to ensure toric markers were properly aligned in those cases. Wounds were sealed with hydration only without use of sutures or sealants in all cases. Qualified ophthalmic technicians or a trained researcher performed the pre and postoperative topography.

Our primary outcome measures were mean magnitude SIA (absolute value of astigmatic change), rate of $\geq 0.50$ D SIA, and the SIA centroids derived from double angle plots. A cutoff value of $\geq 0.50 \mathrm{D}$ was chosen for a significant change in astigmatism based on a comprehensive literature search revealing that to be the upper limit of what Phaco alone would reasonably induce. ${ }^{10-15}$ We also reported and compared $1 \mathrm{~mm}$ and $8 \mathrm{~mm}$ true net power data to determine if the peripheral cornea was experiencing different SIA compared to the central cornea. Since topography isolates the cornea as the source of astigmatism, we also reported double angle plots and centroids for surgically induced refractive astigmatism based on preoperative keratometry measurements compared to postoperative manifest refraction since this would include other sources of astigmatism (eg, lens tilt, decentration, or rotation). The study protocol was approved by the University of Missouri Institutional Review Board, which granted a waiver of consent for this retrospective analysis of existing health records. The prospective portion including repeating of corneal topography was also approved and consents were drafted for the patients to sign. The study followed the tenets of the Declaration of Helsinki, and patient data were collected and maintained with confidentiality.

\section{Statistical Analysis}

Statistical analysis included Welch's $t$-test for comparing means and Fisher's Exact for comparing rates. All statistical analysis was conducted in IBM SPSS Statistics for Windows, version 24 (IBM Corp., Armonk, NY, USA). Doubleangleplots were used to visualize baseline, preoperative, and SIA. Plots were created and centroids derived using a modified version of the tool developed by Abulafiea et al. ${ }^{20}$

\section{Results}

\section{Preoperative Characteristics}

Baseline patient characteristics were consistently similar between the Phaco-KDB and Phaco alone groups (Table 1). Age, gender and ethnicity distribution were comparable. 
Table I Baseline demographic and glaucoma status data

\begin{tabular}{|c|c|c|c|}
\hline $\begin{array}{l}\text { Subject-Level } \\
\text { Parameters }\end{array}$ & $\begin{array}{l}\text { Phaco-KDB } \\
(n=28)\end{array}$ & $\begin{array}{l}\text { Phaco } \\
(n=13)\end{array}$ & $P$-value \\
\hline Age (yr), mean (SD) & $69.9 \pm 9.0$ & $67.8 \pm 9.2$ & 0.409 \\
\hline $\begin{array}{l}\text { Gender, \% (n) } \\
\text { Male } \\
\text { Female }\end{array}$ & $\begin{array}{l}42.9(12) \\
57.1(16)\end{array}$ & $\begin{array}{l}23.1(3) \\
76.9(10)\end{array}$ & 0.308 \\
\hline $\begin{array}{l}\text { Ethnicity, \% (n) } \\
\text { Caucasian } \\
\text { Other* }\end{array}$ & $\begin{array}{l}78.6(22) \\
21.4(6)\end{array}$ & $\begin{array}{l}92.3(12) \\
7.7(1)\end{array}$ & 0.399 \\
\hline Eye-Level Parameters & $\begin{array}{l}\text { KDB-Phaco } \\
(n=42)\end{array}$ & $\begin{array}{l}\text { Phaco } \\
(n=20)\end{array}$ & $P$-value \\
\hline $\begin{array}{l}\text { Glaucoma diagnosis, \% (n) } \\
\text { Primary open-angle } \\
\text { Normal tension } \\
\text { Combined mechanism } \\
\text { Other* }\end{array}$ & $\begin{array}{l}100(42) \\
59.5(25) \\
4.8(2) \\
14.3(6) \\
21.4(9)\end{array}$ & $\begin{array}{l}35.0(7) \\
85.7(6) \\
14.3(1)\end{array}$ & $<0.001$ \\
\hline $\begin{array}{l}\text { Glaucoma severity, \% (n) } \\
\text { Mild } \\
\text { Moderate } \\
\text { Severe }\end{array}$ & $\begin{array}{l}69.0(29) \\
9.5(4) \\
21.4(9)\end{array}$ & $\begin{array}{l}42.9(3) \\
57.1(4)\end{array}$ & \\
\hline Received TORIC IOL, \% (n) & $33.3(14)$ & $35.0(7)$ & 1.00 \\
\hline $\begin{array}{l}\text { Pre-op IOP }(\mathrm{mmHg}) \text {, } \\
\text { mean (SD) }\end{array}$ & I8.4 (8.5) & $15.45(3.3)$ & 0.20 \\
\hline $\begin{array}{l}\text { Post-op IOP }(\mathrm{mmHg}) \\
\text { mean }(\mathrm{SD})\end{array}$ & $15.8(3.9)$ & $12.6(2.6)$ & $<0.01$ \\
\hline $\begin{array}{l}\text { Pre-op Astigmatism (D), } \\
\text { mean (SD) }\end{array}$ & $1.09 \pm 0.6$ & $1.07 \pm 0.9$ & 0.905 \\
\hline Pre-op Axis $\left({ }^{\circ}\right)$, mean (SD) & $102^{\circ} \pm 43.0$ & $106^{\circ} \pm 49.1$ & 0.713 \\
\hline
\end{tabular}

Note: *Other: Pseudoexfoliative glaucoma, pigmentary dispersion glaucoma, primary angle-closure glaucoma.

Naturally, the Phaco-KDB had a significantly higher proportion of glaucomatous eyes than Phaco alone (100\% [42/42] vs $35.0 \%[7 / 20], P<0.001)$. Of the proportion of eyes receiving toric IOLs, preoperative astigmatism magnitude $(1.09 \pm 0.6$ vs $1.07 \pm 0.9, P=1.00)$ and preoperative astigmatism axis $\left(102^{\circ} \pm 43.0\right.$ vs $\left.106^{\circ} \pm 49.1, P=0.905\right)$ were comparable. Baseline astigmatism is plotted in Figure 1.

\section{Surgically Induced Astigmatism}

Table 2 reports comparison of mean magnitude corneal astigmatism, axis change and various cutoffs in magnitude astigmatic value. The difference in mean magnitude astigmatic diopter change was not statistically significant between Phaco-KDB (mean $=0.28,95 \%$ CI: [0.19, $0.37]$ ) and Phaco alone (mean $=0.25,95 \%$ CI: [0.14, 0.35], $P=0.621$, Cohen's $\mathrm{d}=0.12$ ). Likewise, the difference in rate of significant astigmatic diopter $(\geq 0.50$ D) change was not statistically significant between PhacoKDB (11.6\%) and Phaco alone (10.0\%), $(P=1.00$, OR: $1.18, \varphi=-.024)$.

\section{Double Angle Plots}

The postoperative corneal astigmatism data are plotted in Figure 2 and the SIA vector data are plotted in Figure 3. The SIA centroid for Phaco-KDB was $0.05 \mathrm{D} @ 51^{\circ} \pm$ $0.40 \mathrm{D}$ and $0.07 \mathrm{D} @ 3^{\circ} \pm 0.32 \mathrm{D}$ for Phaco alone. These were comparable with the majority of cases experiencing SIA $<0.50$ D. The mean absolute SIA for Phaco-KDB was $0.02 \mathrm{D} \pm 0.40 \mathrm{D}$ and $0.09 \mathrm{D} \pm 0.31 \mathrm{D}$ for Phaco alone.

For surgically induced refractive astigmatism using refractive data, the SIA centroid for Phaco-KDB was 0.12 D@87 $\pm 0.57 \mathrm{D}$ and 0.15 D@64 $\pm 0.43 \mathrm{D}$ for Phaco alone (Figure 4). These were also comparable with the majority of cases experiencing SIA $<0.50 \mathrm{D}$ and the 95\% confidence ellipses of the centroids generously overlapping. The mean absolute SIA for Phaco-KDB was 0.46 $\mathrm{D} \pm 0.33 \mathrm{D}$ and for Phaco alone 0.36 $\mathrm{D} \pm 0.25 \mathrm{D}$.

\section{True Net Power}

We also evaluated SIA at $1 \mathrm{~mm}$ and $8 \mathrm{~mm}$ (Table 3). For Phaco-KDB, the $1 \mathrm{~mm}$ SIA was $0.74 \mathrm{D} \pm 0.91 \mathrm{D}$ and the $8 \mathrm{~mm}$ SIA was $0.43 \mathrm{D} \pm 0.41 \mathrm{D}$. For Phaco alone, the $1 \mathrm{~mm}$ SIA was $0.67 \mathrm{D} \pm 0.54 \mathrm{D}$ and for the $8 \mathrm{~mm}$ SIA was $0.36 \mathrm{D} \pm 0.34 \mathrm{D}$. The difference between $1 \mathrm{~mm}$ and $8 \mathrm{~mm}$ SIA was not significantly different in either group nor was the $1 \mathrm{~mm}$ or $8 \mathrm{~mm}$ SIA significantly different between groups $(P>0.05)$.

\section{Discussion}

Angle surgeries and Schlemm's canal MIGS procedures are often combined with phacoemulsification. Due to their minimal trauma to surrounding tissues and rapid recovery, they are considered compatible with toric or other premium IOLs. Recently, iStent was shown to be astigmatically neutral, ${ }^{17,21}$ and KDB goniotomy has been shown to not increase the rate of "refractive surprise", or miss the refractive target by spherical equivalent greater than \pm 0.50 D. ${ }^{22}$ However, to our knowledge, no studies have reported the effect of KDB goniotomy on surgically induced corneal astigmatism. In this study, we sought to compare the SIA of Phaco-KDB to that of Phaco alone using Scheimpflug topography. Pentacam was repeated at a minimum of 1 month postoperatively to allow for sufficient healing. ${ }^{19}$ 

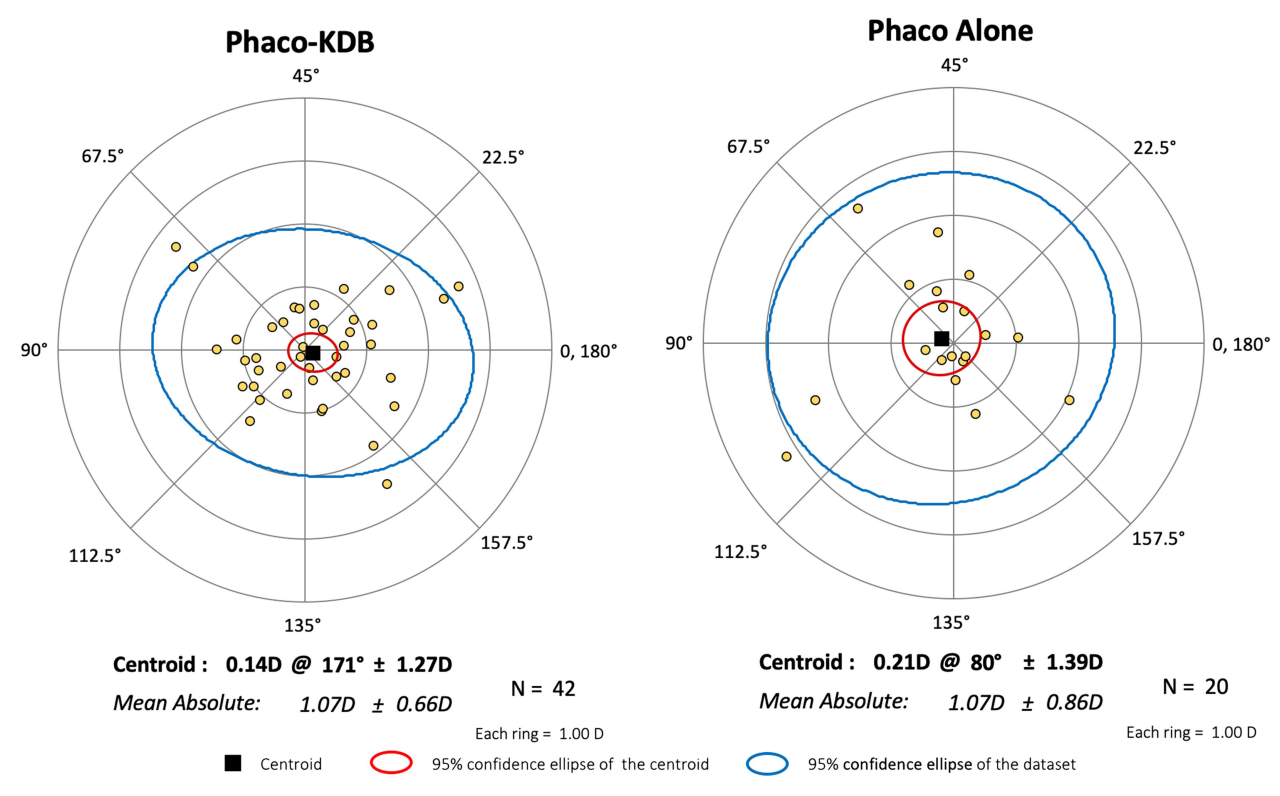

Figure I Baseline corneal astigmatism vectors for Phaco-KDB and Phaco alone.

One source of SIA due to KDB may be excess manipulation of the main wound from the KDB instrument, but it is unlikely given the small size of the KDB instrument compared to the other instruments that the main wound facilitates such as the phaco probe. We hypothesized that the other source of SIA may be the potential for manipulating the anatomy of the nasal angle and our own observation of KDB actually resolving a patient's astigmatism, ${ }^{2}$ so we decided to use baseline and postoperative Pentacam topography to evaluate changes in various corneal values. ${ }^{18}$ Most studies of SIA use biometry data for baseline astigmatism measurement and manifest refraction for postoperative astigmatism. This method is prone to introducing a number of confounders including lens tilt, types, and subjective variance, which can be eliminated by comparing topographic data.

Table 2 Comparison of topography outcomes between PhacoKDB and Phaco alone

\begin{tabular}{|l|l|l|l|}
\hline & $\begin{array}{l}\text { Phaco-KDB } \\
(\mathbf{n = 4 2 )}\end{array}$ & $\begin{array}{l}\text { Phaco } \\
(\mathbf{n = 2 0 )}\end{array}$ & P-value \\
\hline$|\Delta \mathrm{K}|(\mathrm{D})$, mean \pm SD & $0.28 \pm 0.29$ & $0.25 \pm 0.2 \mathrm{I}$ & 0.329 \\
$|\Delta \mathrm{K}| \geq 0.5 \mathrm{D}, \%(\mathrm{n})$ & $\mathrm{II} .6(5 / 42)$ & $10.0(2 / 20)$ & 1.00 \\
$|\Delta \mathrm{K}| \geq 0.75 \mathrm{D}, \%(\mathrm{n})$ & $4.8(2 / 42)$ & $5.0(\mathrm{I} / 20)$ & 1.00 \\
$|\Delta \mathrm{K}| \geq 1.0 \mathrm{D}, \%(\mathrm{n})$ & $2.4(\mathrm{I} / 42)$ & $0(0 / 20)$ & 1.00 \\
$|\Delta \mathrm{K}| \geq 15^{\circ}, \%(\mathrm{n})$ & $21.4(9 / 42)$ & $45.0(9 / 20)$ & 0.075 \\
$|\Delta \mathrm{K}| \geq 30^{\circ}, \%(\mathrm{n})$ & $9.5(4 / 42)$ & $20.0(4 / 20)$ & 0.418 \\
$\mid \Delta$ Axis $\mid\left(^{\circ}\right)$, mean \pm & $15.1 \pm 33.9$ & $22.6 \pm 38.2$ & 0.459 \\
$\mathrm{SD}$ & & & \\
\hline
\end{tabular}

We found that mean magnitude SIA and the rate of clinically significant $(\geq 0.50 \mathrm{D})$ astigmatic change were statistically and clinically similar between Phaco-KDB and Phaco alone, and both procedures resulted in nearly negligible changes in astigmatism. SIA centroids were also comparable and clinically insignificant between the groups and were highly consistent with values reported in existing literature. ${ }^{1-7}$ The double angle plots of our SIA data also showed that the majority of the SIA in both groups were under 0.50 D. As a general observation, SIA in Phaco alone appeared to be more randomly spread in axis, whereas Phaco-KDB tended to show a preference to either mostly with-the-rule or mostly against-the-rule with fewer of the values in between. It is important to remember with the double angle plots, the axis is doubled so against-therule astigmatism is all on the right of the plot along the $180^{\circ}$ axis and with-the-rule astigmatism is all on the left along the $90^{\circ}$ axis.

Since topography only evaluates the corneal portion of astigmatism (which was the concern that prompted this study based on our previous case report), we also reported the double angle plots and centroids for surgically induced refractive astigmatism based on patient's preoperative keratometry measurements compared to postoperative manifest refraction for completeness. This would theoretically subtract out the preoperative corneal astigmatism and the remaining causes would be due to changes in the lens positioning. We initially had a concern about lens tilt contributing to SIA especially 

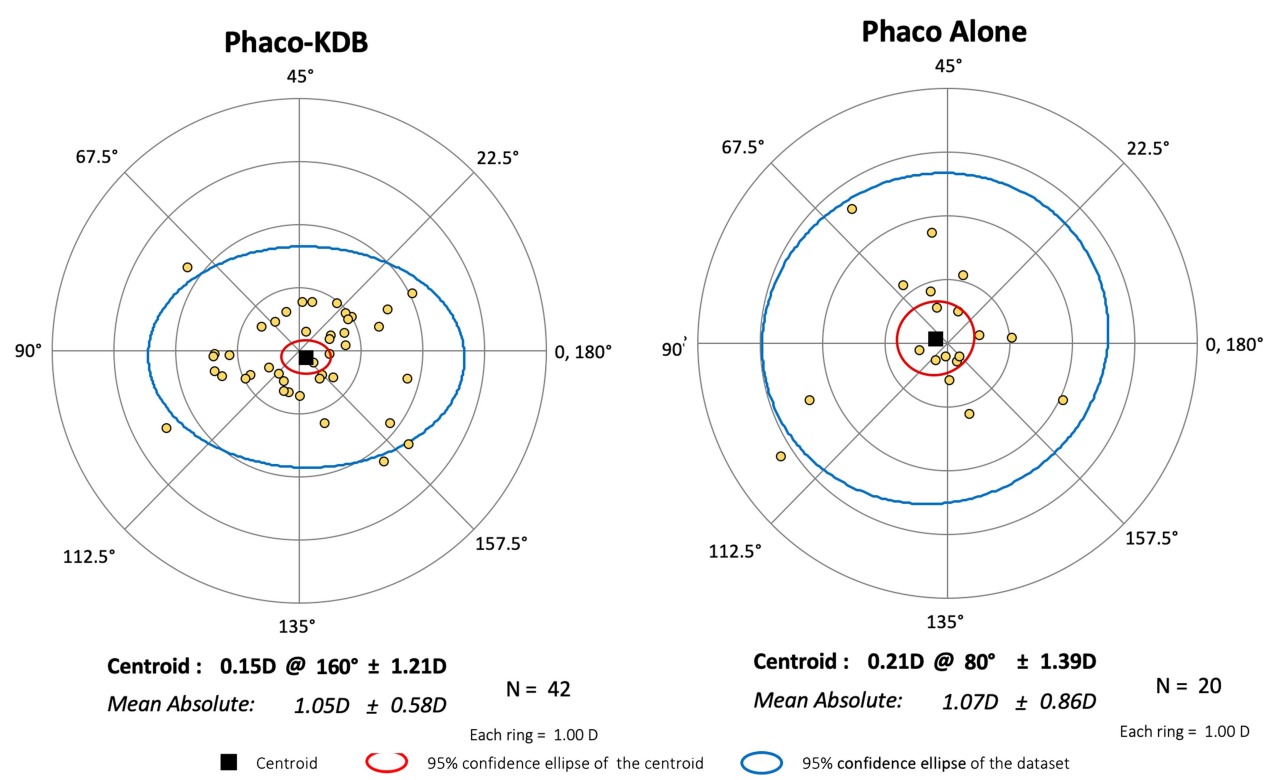

Figure 2 Postoperative corneal astigmatism vectors for Phaco-KDB and Phaco alone.
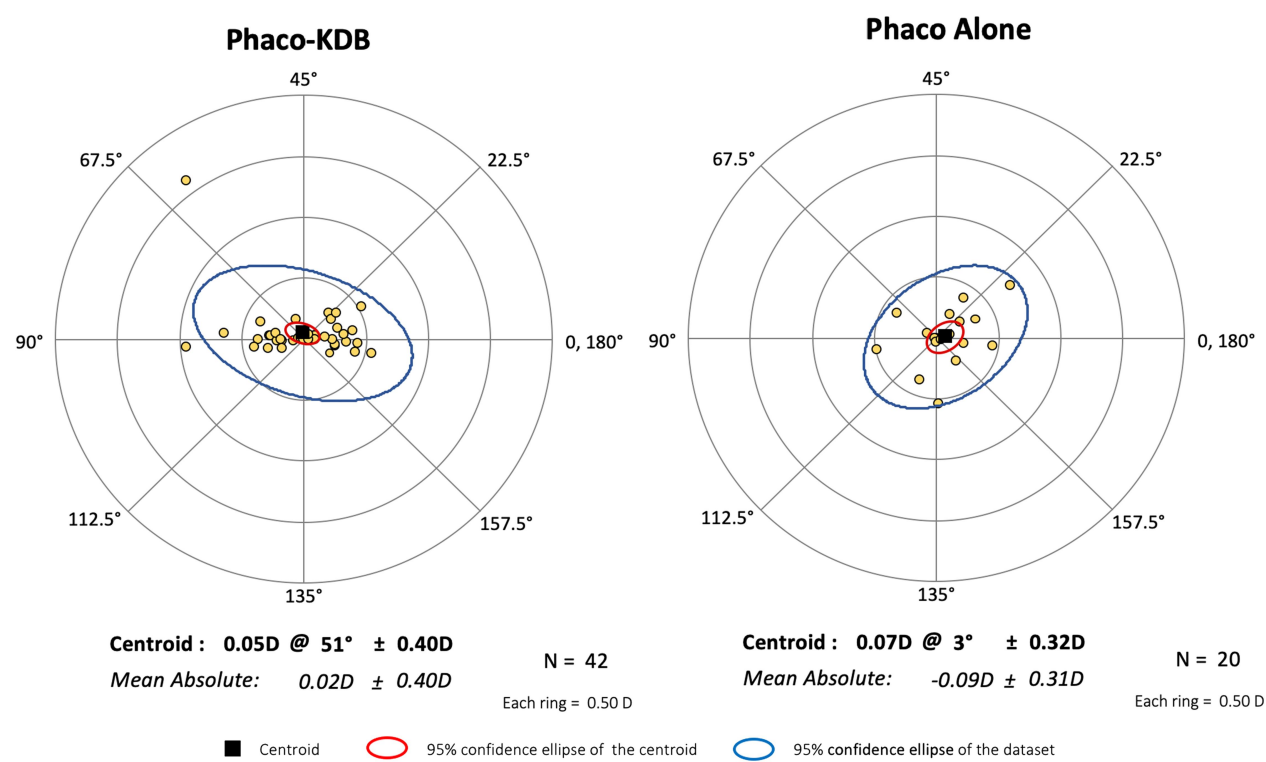

Figure 3 Surgically induced corneal astigmatism of Phaco-KDB and Phaco alone.

since the KDB is only performed over the nasal angle and there is a theoretical possibility of increased zonular laxity. However, we found the refractive astigmatism centroids for Phaco-KDB and Phaco alone to be comparable and there was no clinical evidence of zonular laxity in any cases we observed. The question of possible lens tilt may be further quantified using ultrasound biomicroscopy or B-scan in future studies.

The main limitation of the study includes difficulty in ensuring high and reliable imaging quality while obtaining topography, and many patients were eliminated for this reason. The non-randomized nature of this study may have introduced confounders. However, the baseline characteristics including the number of toric IOL used were comparable between both groups.

Power calculation revealed that a total of 32 eyes are required to detect a significant difference in the samples with a power of $80 \%$ with the chi-square test of homogeneity. However, we admit that our sample size was near the minimum required for the comparisons of means in the 

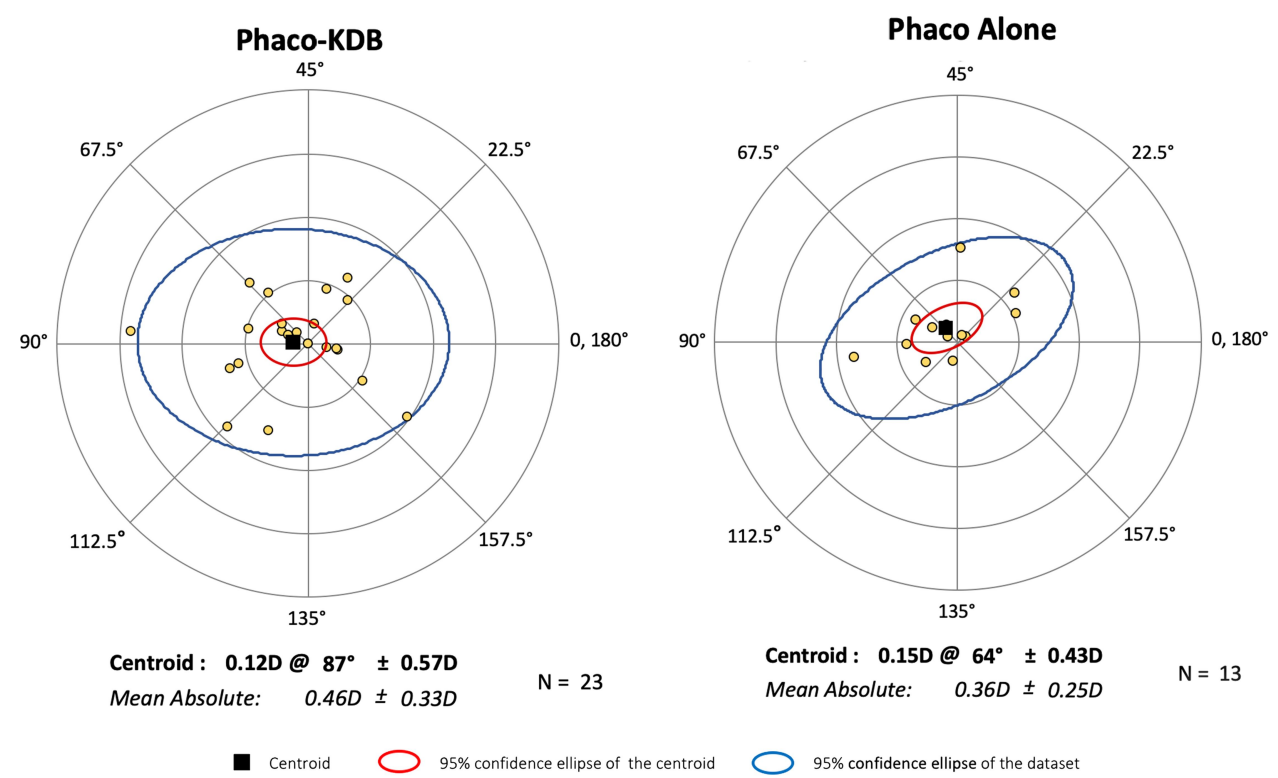

Figure 4 Surgically induced refractive astigmatism of Phaco-KDB and Phaco alone.

context of SIA. Despite these limitations, our data is consistent with similarly powered existing literature on SIA. ${ }^{3,4,7}$

Here, we have shown that KDB performed at the time of phacoemulsification is likely to be astigmatically neutral based on pre- and postoperative corneal topography using the simK values from the Pentacam Holladay report. This suggests that refractive surgeons may not need to make any special considerations in their IOL calculations when performing KDB. Surgeons likely can expect a comparable SIA to when they perform Phaco alone and do not need to adjust their personal surgeon factor when adding the KDB procedure.

\section{Disclosure}

Jella An reports non-financial support from New World Medical, outside the submitted work. The authors report no other potential conflicts of interest for this work.

Table 3 Concentric surgically induced corneal astigmatism data at $1 \mathrm{~mm}$ and $8 \mathrm{~mm}$

\begin{tabular}{|l|l|l|l|}
\hline & $\begin{array}{l}\text { Phaco- } \\
\text { KDB } \\
(\mathbf{n}=40)\end{array}$ & $\begin{array}{l}\text { Phaco } \\
(\mathbf{n}=\mathbf{1 4})\end{array}$ & P-value \\
\hline$|\Delta K|(D) I m m$, mean \pm SD & $0.74 \pm 0.9 \mid$ & $0.67 \pm 0.54$ & 0.786 \\
$|\Delta K|(D) 8 m m$, mean \pm SD & $0.43 \pm 0.4 \mid$ & $0.36 \pm 0.34$ & 0.540 \\
$P$-Value & 0.054 & 0.077 & \\
\hline
\end{tabular}

\section{References}

1. Ferreira T, Ribeiro F, Pinheiro J, Ribeiro P, O’Neill J. Comparison of surgically induced astigmatism and morphologic features resulting from femtosecond laser and manual clear corneal incisions for cataract surgery. $J$ Cataract Refract Surg. 2018;34(5):322-329. doi:10.3928/1081597X-20180301-01

2. Kawahara A, Kurosaka D, Yoshida A. Comparison of surgically induced astigmatism between one-handed and two-handed cataract surgery techniques. Clin Ophthalmology. 2013;7:1967-1972. doi:10.2147/OPTH.S52415

3. Yang J, Wang X, Zhang H, Pang Y, Rui-Hua W. Clinical evaluation of surgery-induced astigmatism in cataract surgery using $2.2 \mathrm{~mm}$ or $1.8 \mathrm{~mm}$ clear corneal micro-incisions. Int J Ophthalmol. 2017;10(1):68-71.

4. Diakonis V, Yesilirmak N, Cabot F, et al. Comparison of surgically induced astigmatism between femtosecond laser and manual clear corneal incisions for cataract surgery. $J$ Cataract Refract Surg. 2015;41(10):2075-2080. doi:10.1016/j.jcrs.2015.11.004

5. Wang J, Zhang E, Fan W, Ma J, Zhao P. The effect of micro-incision and small-incision coaxial phaco-emulsification on corneal astigmatism. Clin Exp Ophthalmol. 2009;37(7):664-669. doi:10.11 11/j.1442-9071.2009.02117.x

6. Can I, Takmaz T, Yildiz Y, Bayhan H, Soyugelen G, Bostanci B. Coaxial, microcoaxial, and biaxial microincision cataract surgery: prospective comparative study. J Cataract Refract Surg. 2010;36 (5):740-746. doi:10.1016/j.jcrs.2009.11.013

7. Khandelwal S, De Oca M. The end of an era: smaller incisions in modern cataract surgery reduce the impact of surgically induced astigmatism. Cataract Refract Surg Today. 2017.

8. Hill W. Expected effects of surgically induced astigmatism on AcrySof toric intraocular lens results. J Cataract Refract Surg. 2008;34(3):36407. doi:10.1016/j.jcrs.2007.10.024

9. Ernest P, Hill W, Potvin R. Minimizing surgically induced astigmatism at the time of cataract surgery using a square posterior limbal incision. J Ophthalmol. 2011;2011.

10. Monaco G, Scialdone A. Long-term outcomes of limbal relaxing incisions during cataract surgery: aberrometric analysis. Clin OPhthlamology. 2015;9:1581-1587. doi:10.2147/OPTH.S89 024 
11. Tejedor J, Murube J. Choosing the location of corneal incision based on preexisting astigmatism in phacoemulsification. Am J Ophthalmol. 2005;139(5):767-776. doi:10.1016/j.ajo.2004.12.057

12. Xue K, Jolly J, Mall S, Haldar S, Rosen P, MacLaren R. Real-world refractive outcomes of toric intraocular lens implantation in a United Kingdom National Health Service setting. BMC Ophthalmol. 2018;18 (1):30. doi:10.1186/s12886-018-0692-7

13. Chen D, Sng C. Safety and efficacy of microinvasive glaucoma surgery. J Ophthalmol. 2017.

14. Richter G, Coleman A. Minimally invasive glaucoma surgery: current status and future prospects. Clin Ophthalmol. 2016;10:189-206.

15. Lee GA, Porter AJ, Vincent RA, Makk J, Vincent SJ. Combined phacoemulsification and microinvasive glaucoma surgery in comparison to phacoemulsification alone for open angle glaucoma. Eye. 2019. doi:10.1038/s41433-019-0459-2

16. Directions for use for the kahook dual blade ${ }^{\circledR}$; November 2018 Available from: https://www.newworldmedical.com/Clients/ NewWorldMedical/Content/NWMCorp/media/pdf/KDB_Product_ Brochure IFU revE 50-0069.pdf. Accessed October 3, 2019.

17. Chan H, Kong Y. Glaucoma surgery and induced astigmatism: a systematic review. Eye Vis. 2017;4:27. doi:10.1186/s40662-0170090-x
18. Hirabayashi M, McDaniel L, J. Reversal of toric intraocular lens-corrected corneal astigmatism after kahook dual blade goniotomy. J Curr Glaucoma Pract. 2019;13(1):42-44. doi:10.50 05/jp-journals-10078-1243

19. Matossian C, Makari S, Potvin R. Cataract surgery and methods of wound closure: a review. Clin Ophthalmol Auckl NZ. 2015;9: 921-928. doi:10.2147/OPTH.S83552

20. Abulafiea A, Koch D, Holladay J, Wang L, Hill W. Pursuing Perfection in IOL Calculations IV: astigmatism analysis, SIA and double angle plots. J Cataract Refract Surg. 2018;44(10):1169-1174.

21. Scott R, Tanner F, Stephens J, Berdahl J. Refractive outcomes after trabecular microbypass stent with cataract extraction in open-angle glaucoma. Clin Ophthalmol. 13:1331-1340. doi:10.2147/OPTH.S2 06619

22. Young C, Sieck E, Epstein R, et al. Refractive outcomes among glaucoma patients undergoing phacoemulsification cataract extraction with and without kahook dual blade goniotomy. Poster presented at the: American Glaucoma Society 29th Annual Meeting; March 2019; San Francisco, California.
Clinical Ophthalmology

\section{Publish your work in this journal}

Clinical Ophthalmology is an international, peer-reviewed journal covering all subspecialties within ophthalmology. Key topics include: Optometry; Visual science; Pharmacology and drug therapy in eye diseases; Basic Sciences; Primary and Secondary eye care; Patient Safety and Quality of Care Improvements. This journal is indexed on PubMed
Dovepress

Central and CAS, and is the official journal of The Society of Clinical Ophthalmology (SCO). The manuscript management system is completely online and includes a very quick and fair peer-review system, which is all easy to use. Visit http://www.dovepress.com/ testimonials.php to read real quotes from published authors. 